アコースティックエミッション法を用いた付着性二枚貝の配管付着状態検出法の開発

松尾卓摩 ${ }^{1) *}$ ・長 秀雄 ${ }^{11}$

1) 青山学院大学理工学部機械創造工学科 †252-5258＼cjkstart神奈川県相模原市中央区淵野辺5-10-1-J201

\title{
Development of a method to detect pipe clogging caused by sessile bivalves, utilizing an acoustic emission technique
}

Takuma Matsuo, ${ }^{1)}$ and Hideo Cho, ${ }^{1)}$

1) Faculty of Science and Engineering, Aoyama Gakuin University, 5-10-1 Fuchinobe, Chuo, Sagamihara, Kanagawa 252-5258, Japan

* Corresponding author (T. Matsuo)

E-mail: matsuo@me.aoyama.ac.jp

(Received August 31, 2011; Accepted December 26, 2011)

\begin{abstract}
Clogging of water intake pipes by sessile bivalves is a serious problem hindering the safe operation of industrial and power plants. We developed a system to monitor such clogging by means of an acoustic emission (AE) technique. A sheet-type optical fiber sensor developed in our laboratory was used to monitor AE signals produced by single individuals or colonies of mussel Mytilus galloprovincialis attached by their byssus inside a PMMA pipe. No relation was found between mussel size and peak frequency of AE signal; However, the mussels each had a characteristics frequency, and the scattering of AE signals frequencies corresponded to the number of mussels in a colony. In addition, the AE signal generation rate increased with increasing numbers of mussels in the pipe, but continuous monitoring showed that the signal generation rate also increased when mussels were removed. Continuous monitoring is thus needed if pipe clogging is to be monitored effectively by this AE technique.
\end{abstract}

Key words: Limnoperna fortunei, acoustic emission, optical fiber sensor, pipe, cylinder wave

\section{1. 序論}

近年、水道施設等の取水設備においてカワヒバリガイ Limnoperna fortunei の配管への侵入が多く発生し、取 水能力の低下や死滅個体による着臭、計器の異常などが 問題となっている (Magara et al., 2001, Nagaya et a1., 2001)。これらの対策には様々な研究が行われてい るが (Matsui et al., 2002, 坂口ら, 2009)、既存の上 水道施設では使用できる手段が限定される。そのため、 現状では駆除のためには定期的な配管の分解清掃が必要 となる。しかし細径配管へ侵入した場合は短期間で閉塞 する恐れがあるため貝の侵入をできるだけ早期に検知す
る必要がある。そこで本研究では、細径の配管への貝の 付着の発生の有無及び付着量をリアルタイムで評価でき る技術として、アコースティックエミッション（AE）を 用いた手法を提案する。著者らはいままでに、配管に付 着した付着性二枚貝は流れによって振動し、貝と管壁も しくは群生した貝同士が衝突することによって発生した 弾性波（AE信号）を検出することに成功し、AE信号の発 生の有無は配管内の液流速や貝の付着する向きに依存す ることを明らかにした（Matsuo et al.，2009）。しかし、 貝の付着個体数等の付着状態と $\mathrm{AE}$ 発生挙動の関係は明ら かではなかった。そこで本研究では、配管内に付着した 
貝の個体数をパラメータとしてAE信号の発生頻度との関 連を検討した。また貝が付着した状態で、流速一定の条 件で数日間の $\mathrm{AE}$ モニタリングを行い、 $\mathrm{AE}$ 発生数の変化 を調べた。これらの結果から AE 法を用いた配管内の貝 の付着状態評価手法の可能性を検討した。なお、カワヒ バリガイは特定外来生物に指定されており研究室での実 験は環境省の許可が必要となる。そこで、実験は海産の 付着性二枚貝であるムラサキイガイ Mytilus galloprovincialis 用いて行った。

\section{2. 光ファイバセンサを用いた $A E$ 信号計測システム}

$\mathrm{AE}$ 計測では一般的に圧電素子を用いたセンサを使用 するが、防水性が低いことや広範囲のモニタリングには 複数のセンサが必要などの問題がある。そこで本研究で は $\mathrm{AE}$ 信号計測装置として、光ファイバを用いた $\mathrm{AE}$ 計測 システム（Matsuo et al. ，2009）（以後、OFSと表記） を用いた。光ファイバセンサはセンサ部に電気を使用し ない光ファイバであるため、水中や高湿度環境下でも使 用でき、 1 本の光ファイバで複数個所の同時計測も可能 である。Fig. 1 に OFS のシステム構成図を示す。本シ ステムはホモダイン・マッハツェンダ型干渉計である。 ダイオードレーザから発振したレーザ光を、スプリッタ を用いて 2 本の通信用光ファイバ（センサ用と参照用） に分岐し、再びカプラによって結合する。センサ用ファ イバは検査対象表面に設置し、AEによって誘起される 光ファイバの伸縮に伴う光の位相変調を参照用レーザと 干渉させ、フォトダイオードで光の強弱として検出する ことでAEを検出する。検出した信号は自作したフィー ドバック回路を用いて、10 kHz 以下の低周波数のノイ ズを除去するとともに感度の安定化を行っている（Cho et al. , 2005)。また、参照光とセンサ光の偏光は、計 測前にあらかじめ手動で一致させた。また、センサ用ファ イバは Fig. 2 に示すように光ファイバをコイル状に巻 き、ポリイミドテープで挟んで固定したシート型のセン サを用いた。本センサは配管を伝搬する $\mathrm{AE}$ モニタリン グ用に著者らが以前に開発したものであり、センサはコ イル直径Wを変化させることで周波数特性を制御できる
(Matsuo et al., 2009)。今回は $W=47 \mathrm{~mm}$ とて、周波 数 $18 \mathrm{kHz}$ 近傍で高い感度を有している。

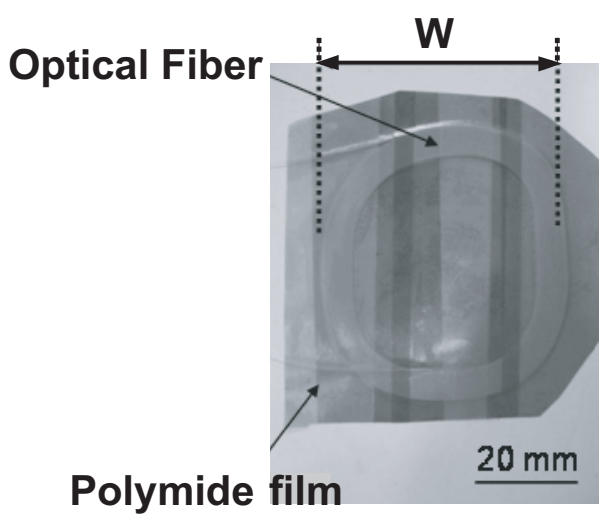

Fig. 2 A sheet-type optical fiber sensor.

\section{3. 貝の付着状態と $A E$ 発生挙動の関係}

\section{1 実験方法}

ムラサキイガイの生体を用いて、配管内の貝の付着個 体数と検出 $\mathrm{AE}$ のピーク周波数の関係を調べた。実験装 置図をFig. 3 に示す。なお実験に使用した配管及び計 測装置は前報（Matsuo et al.，2009）とほぼ同じであ る。配管には、内部の状態が観察できるように外径 $30 \mathrm{~mm}$ 肉厚 $2 \mathrm{~mm}$ 、長さ $1 \mathrm{~m}$ のアクリルパイプを用いた。 ムラサキイガイ生体を管内に 1 個体もしくは複数個体 （ 2 ～300個体）を入れ、室温 $26^{\circ} \mathrm{C}$ の環境で人工海水中 に 1 日間放置して付着させた。その後、流速 0.97-1.45 $\mathrm{m} / \mathrm{s}$ で人工海水を循環させ、実験を行った。なお、本実 験では付着個体数が 1 個の実験では殼長 7-25 mm の貝 を用いて 8 回実験を行い、そのうち $\mathrm{AE}$ が発生した 7 回 のデータを用いた。付着個体数が複数個（コロニーを 形成）の貝を用いた実験では、殼長 2-20 mm の貝を用い て 16 回行った。AE は貝（又はコロニー）から約 $250 \mathrm{~mm}$ 離れた位置の管外表面に巻き付けたシート型センサで計 測した。各実験ともに 1 回の計測は数分間行い、計測後

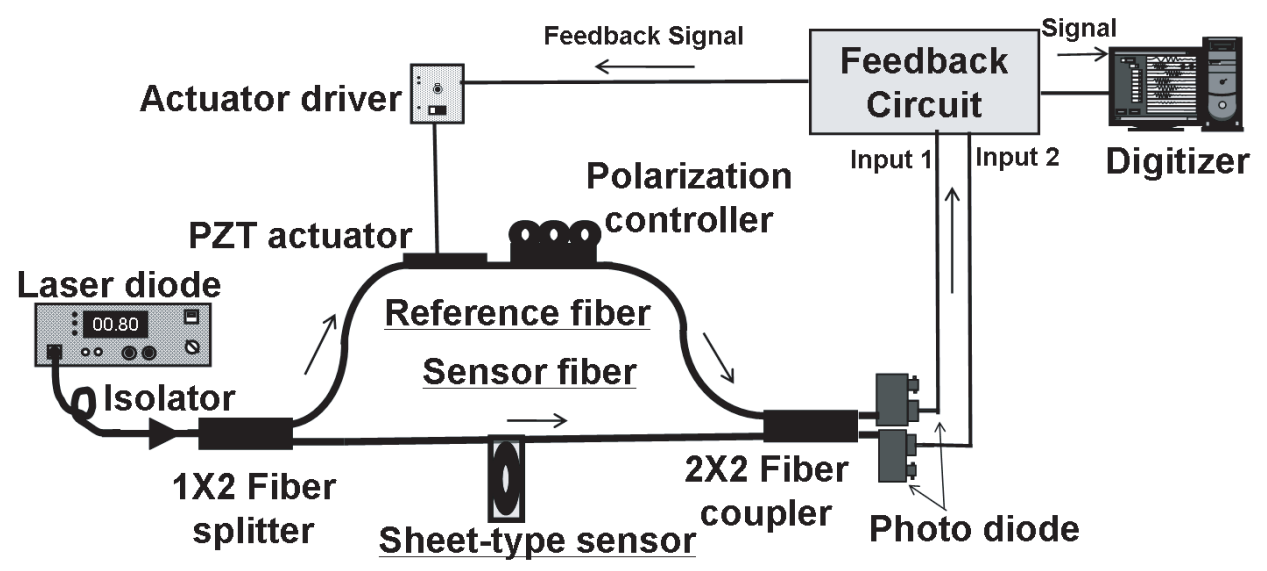

Fig. 1 Illustration of the optical fiber AE monitoring system (OFS) used in this study. 
1 分間あたりの平均 $\mathrm{AE}$ 発生数を算出した。なお、前報 (Matsuo et al. , 2009) と貝の順致日数が異なるため、 AE の発生し始める流速が異なっている。

\section{2 実験結果及び考察}

Fig. 4 に管内に殼長 $11 \mathrm{~mm}$ の貝を 1 個体付着させ、流 速 $0.97 \mathrm{~m} / \mathrm{s}$ で人工海水を循環させたときに得られた代 表的なAE波形とその周波数スペクトルを示す。検出した $\mathrm{AE}$ 信号は持続時間が約 $1 \mathrm{~ms}$ 前後で収束する突発型の波 であり、連続的に発生する流れによる振動とは明瞭に区 別することが可能であった。また、周波数スペクトルは

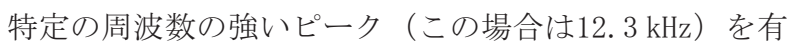

していた。Fig. 5 にFig. 4 と同一の個体に対して流速 を 0.97、1.25、1. $45 \mathrm{~m} / \mathrm{s}$ に変化させ、 1 分間 $\mathrm{AE}$ 計測を 行った時に得られた $\mathrm{AE}$ 信号の最大ピーク周波数の分布 を示す。いずれの流速においても発生する $\mathrm{AE}$ のピーク 周波数にはばらつきがあったが、ばらつきの傾向に変化 は見られず、ピーク周波数が $12.3 \mathrm{kHz}$ の $\mathrm{AE}$ 信号が最も 多く検出された。付着個体数が 1 個の場合の付着個体の 款長と検出 $\mathrm{AE}$ の最大ピーク周波数の関係を Fig. 6 に示 す。なお、殸長 $7 \mathrm{~mm}$ の個体では $\mathrm{AE}$ が発生しなかったた め、他の 7 個体での結果を図中に示す。貝は個体ごとに 異なるピーク周波数を有していた。また、同じ殸長の個 体であってもピーク周波数が異なっており、殼長と $\mathrm{AE}$

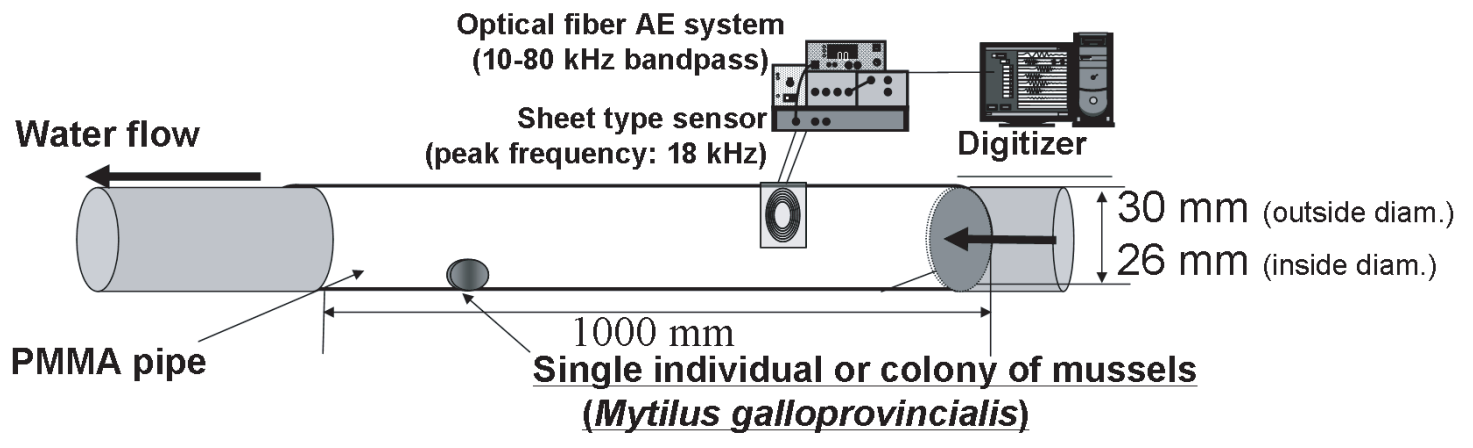

Fig. 3 Experimental setup for monitoring AE signals generated by mussels (from Matsuo et al., 2009).
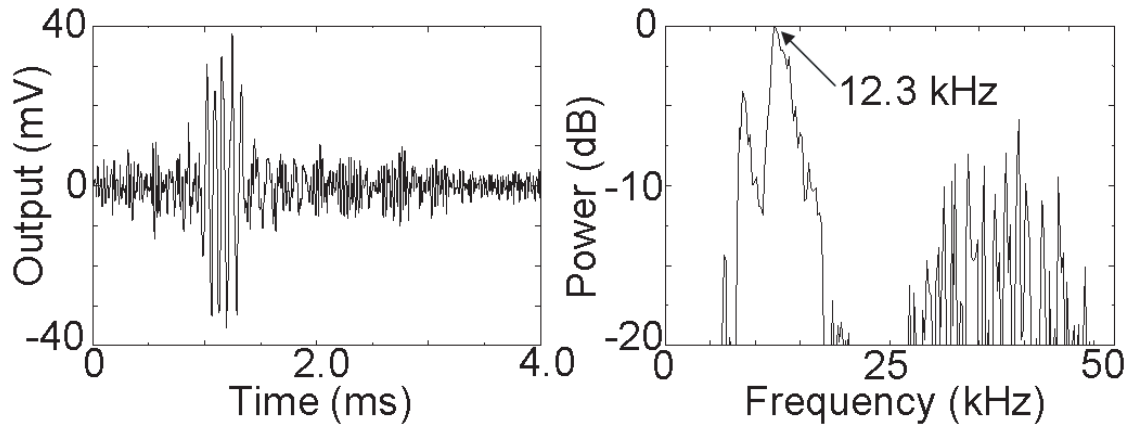

Fig. 4 Typical AE waveform (left) and its power spectrum (right).

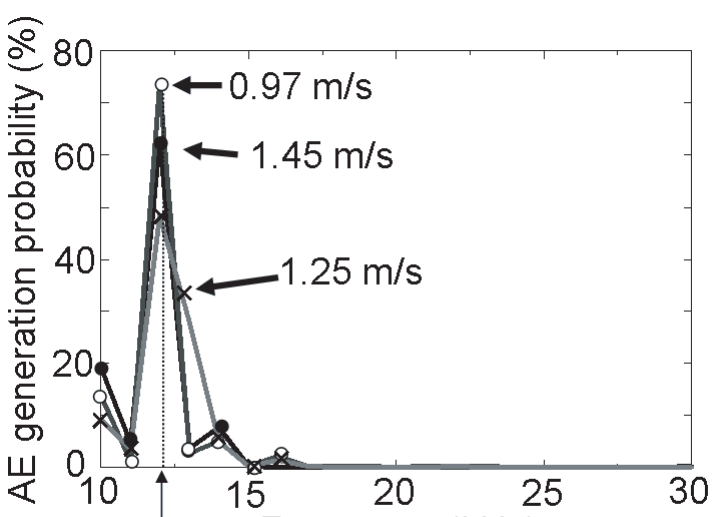

12.3 Frequency $(\mathrm{kHz})$

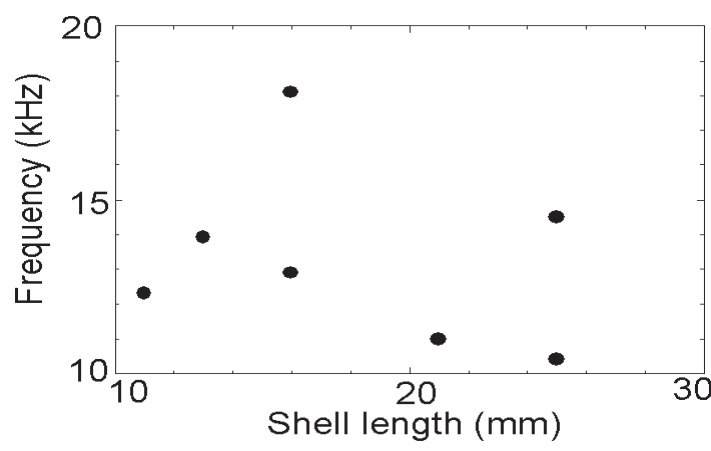

Fig. 6 Relationship between shell length and peak frequency of $\mathrm{AE}$ waveforms recorded from individual mussels.

Fig. 5 Probability of peak frequency of AE produced by one mussel on inner surface of pipe in various flow rates. 
信号のピーク周波数に関連は見られなかった。Fig. 7 に流速 $0.97 \mathrm{~m} / \mathrm{s}$ の管内に複数個体を付着させたコロニー （個体数 $4 、 7 、 14 ）$ から発生した $\mathrm{AE}$ 信号の最大ピーク 周波数の頻度を示す。個体数 1 の場合と異なり、最大ピー クが存在する周波数にはばらつきがあり、そのばらつき は多くの貝が付着した管ほど大きい。これは、貝は個体 ごとに異なる周波数の $\mathrm{AE}$ が発生しているため、付着数 が多いほど様々な周波数ピークを有する $\mathrm{AE}$ 信号が検出 されるためと考えられる。また、流速が変化した場合に おいても、この傾向は同様であった。

次に管内に付着した貝の付着状態と $\mathrm{AE}$ 発生数につい て検討した。Fig. 8 に流速 $0.97 \mathrm{~m} / \mathrm{s}$ における付着個体 数と 1 分当たりの $\mathrm{AE}$ 発生頻度を示す。管内に付着した 個体数が増加すると、発生する $\mathrm{AE}$ 数が直線的に増加し ている。しかし、個体数が少ない管では、 $\mathrm{AE}$ 発生数に ばらつきが見られる。これは貝の付着間隔の影響と考え られ、付着個体数が少ない場合では個体数の詳細な評価 は難しいと考えられる。しかし、貝が付着すれば突発的 な $\mathrm{AE} ゙$ 検出されること、複数個の貝が存在すれば $\mathrm{AE}$ 数 から大まかな付着状態が評価できる可能性があることが

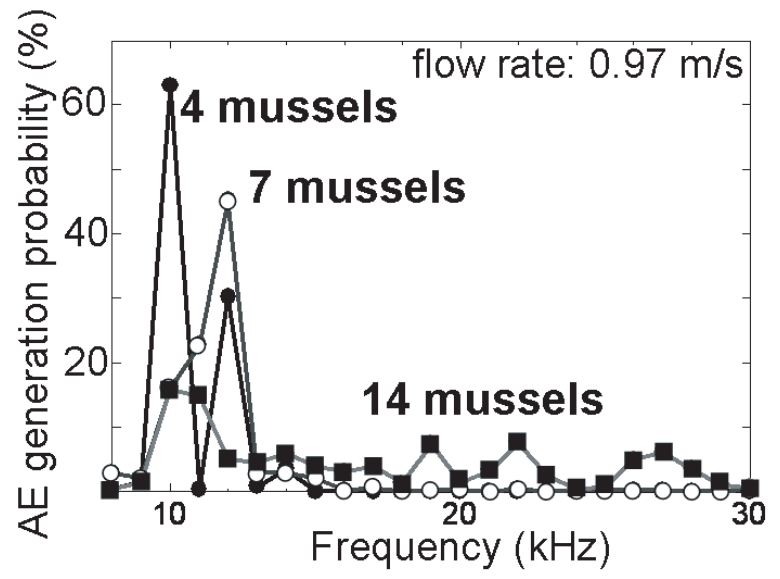

Fig. 7 Peak AE frequency distributions recorded from different-sized mussel colonies in 1 minute of monitoring.

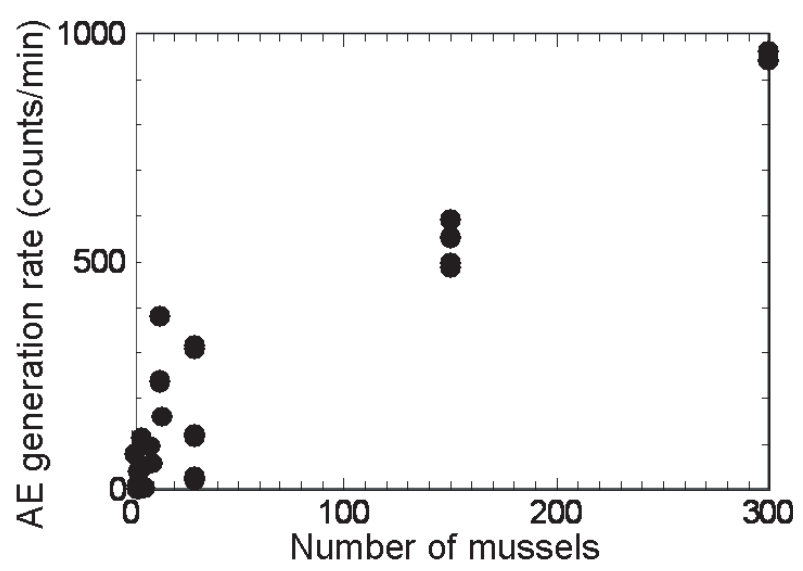

Fig. 8 Relationship between AE generation rate and number of mussels in the pipe.
わかった。また付着状態の定量的な評価にはガイド波を 使用する手法（Cho et al.，2009） も提案されており、 他の方法と併用寸ることで定量的な評価が可能になる可 能性がある。

\section{4. 連続モニタリングにおけるAE発生数の変化}

\section{1 実験方法}

実験装置はFig. 3 と同様の装置を用いて、Fig. 9 に 示す付着個体数 13 (Pipe A) と 7 (Pipe B) の 2 種類の 配管を用いて、人工海水を流速 $1.33 \mathrm{~m} / \mathrm{s}$ で循環させた。 $\mathrm{AE}$ 計測はFig. 3 と同様にコロニー中心から $250 \mathrm{~mm}$ の位 置にセンサを設置して1日当たり数回、1分間の計測を行っ た。
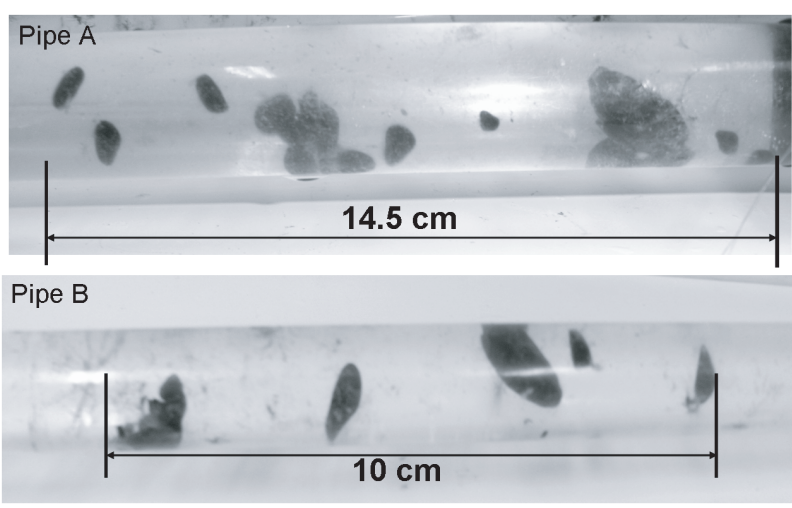

Fig. 9 Two pipes (A and B) with 7 and 13 mussels respectively.

\section{2 実験結果及び考察}

計測結果をFig. 10 に示す。Pipe A では 1 分間当た りの $\mathrm{AE}$ 発生数は 15 回前後とほとんど変化は無かった。 Pipe B では実験開始直後のAEは 50 回ほどであったが、 実験開始 2 日半後にそれまでの約 3 倍の個数の $\mathrm{AE}$ が計 測され、その後再び 50 回程度に低下している。今回使 用した 2 本の管に付着した貝の個体数が少ないため $\mathrm{AE}$ 数と付着個体数に相関が無く、付着個体数が少ない Pipe B の方が発生する AE 数が多くなった。また、実験 後に管内を観察すると、Pipe B では複数個の貝が管か ら離脱していた。貝は複数の足系によって付着している が、このうちの数本の足系が切れた場合、流れによって 貝が激しく振動し、管壁と衝突する様子が観察された。 つまり、Pipe B において $\mathrm{AE}$ 発生数が一時的に増加した 原因は、貝の離脱過程での管壁との衝突が原因と考えら れる。すなわち、貝が離脱直前の管では $\mathrm{AE}$ が多く発生 する。この様な場合 $\mathrm{AE}$ 数を用いて付着状態を正しく評

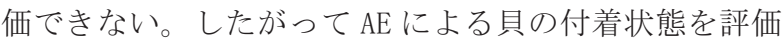
するためには比較的長期間計測を行い、 $\mathrm{AE}$ の発生頻度 の推移を見極め、一時的に $\mathrm{AE}$ 数が変化したデータを除 く必要があることがわかった。 

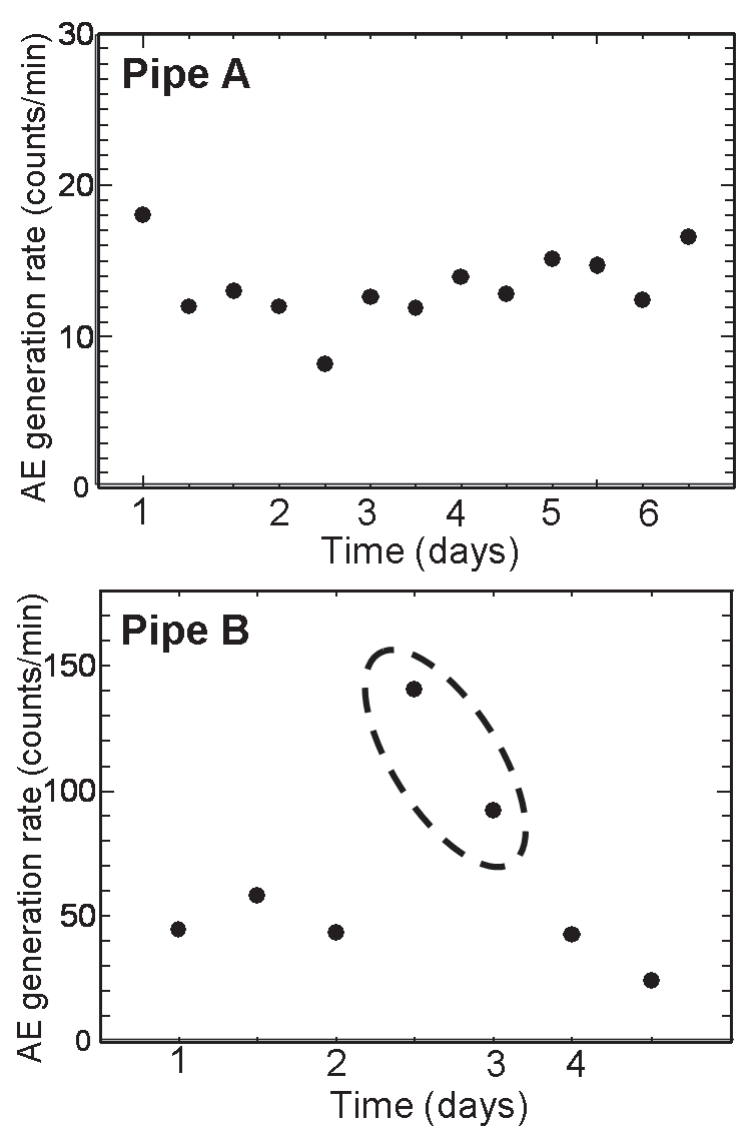

Fig. 10 Change in $\mathrm{AE}$ generation rate with time for pipe A (upper) and pipe B (lower).

\section{5. 結論}

$\mathrm{AE}$ を用いた付着性二枚貝の管付着個体数の評価手法 の検討を行った。光ファイバ $\mathrm{AE}$ 計測システムを用いて 配管内に付着した貝の個体数と $\mathrm{AE}$ 波形の周波数の関係 について調べた結果、貝は個体ごとに異なるピーク周波 数を有する $\mathrm{AE}$ を発生していた。また、管内の付着個体
数が多い管ほど $\mathrm{AE}$ 発生数が多い傾向が見られ、 $\mathrm{AE}$ 数か ら大まかな付着個体数の推定が可能であった。また、数 日間のモニタリング行った結果、貝が管壁から離脱する 際に一時的に $\mathrm{AE}$ 発生数が増加した。よって、AE を用い て管内の状態を評価するためには長期的なモニタリング を行い、一時的に $\mathrm{AE}$ 数が変化したデータを除いて評価 に用いる必要がある。

\section{謝 辞}

本研究は、青山学院大学卒業生（現 スズキ(株）水野 雄太氏の協力によって行われた。また、日本NUS(侏) 勝山 一朗氏、日揮(株) 門万寿夫氏の両氏には様々な助言を 頂いた。記して謝意を示す。

\section{引用文献}

Magara, Y., Y. Matsui, Y. Goto and A. Yuasa (2001). Invasion of the non-indigenous nuisance mussel, Limnoperna fortunei, into water supply facilities in Japan. J. Water Supply, 50 (3), 113124.

Nagaya, K., Y. Matsui, H. Ohira and A. Yuasa (2001). Attachment strength of an adhesive nuisance mussel, Limnoperna fortunei, against water flow. Biofouling, 17 (4), 263-274.

Matsui, Y., K. Nagaya, G. Funahashi, Y. Goto, A. Yuasa, H. Yamamoto, K. Ohkawa and Y. Magara (2002). Effectiveness of antifouling coatings and water flow in controlling attachment of the nuisance mussel Limnoperna fortunei. Biofouling, 18 (2), 137-148.

坂口勇・小林卓也・中野大助 (2009). カワヒバリガイ防除に関 する基礎的検討. Sessile Organisms, 26 (2), 98.

Matsuo, T., Y. Mizuno and H. Cho (2009). Monitoring of pipe clogging by mussels utilizing an optical fiber AE system. J. AE, 27, 224-232.

Cho, H., R. Arai, and M. Takemoto (2005). Development of stabilized and high sensitive optical fiber acoustic emission system and its application. J. $A E, 23,72-80$.

Cho, H., T. Abe and T. Matsuo (2009). Quantitative evaluation of the blocking ratio of a blockage inside a pipe utilizing film-type PZT elements. J. Solid Mech. Mat. Eng., 3(2), 278-286 